\title{
Role of the prion protein family in the gonads
}

\author{
Aurélie Allais-Bonnet and Eric Pailhoux* \\ Institut National de la Recherche Agronomique, UMR 1198, Biologie du Développement et Reproduction, Jouy-en-Josas, France
}

\section{Edited by:}

Jean-Luc Vilotte, National Institute of Agronomical Research, France

\section{Reviewed by:}

Rafael Linden, Federal University of

Rio de Janeiro, Brazil

Reiner A. Veitia, Paris

Diderot, France

${ }^{*}$ Correspondence:

Eric Pailhoux, Institut National de la Recherche Agronomique, UMR

1198, Biologie du Développement et Reproduction, Bâtiment 440,

F-78350 Jouy-en-Josas, France e-mail: eric.pailhoux@jouy.inra.fr
The prion-gene family comprises four members named PRNP (PRPC), PRND (Doppel), PRNT (PRT), and SPRN (Shadoo). According to species, PRND is located $16-52 \mathrm{~kb}$ downstream from the PRNP locus, whereas SPRN is located on another chromosome. The fourth prion-family gene, $P R N T$, belongs to the same genomic cluster as PRNP and $P R N D$ in humans and bovidae. PRNT and PRND possibly resulted from a duplication event of $P R N D$ and $P R N P$, respectively, that occurred early during eutherian species divergence. Although most of the studies concerning the prion-family has been done on $\mathrm{PRP}^{\mathrm{C}}$ and its involvement in transmissible neurodegenerative disorders, different works report some potential roles of these proteins in the reproductive function of both sexes. Among them, a clear role of $P R N D$, that encodes for the Doppel protein, in male fertility has been demonstrated through gene targeting studies in mice. In other species, Doppel seems to play a role in testis and ovary development but its cellular localization is variable according to the gonadal developmental stage and to the mammalian species considered. For the other three genes, their roles in reproductive function appear ill-defined and/or controversial. The present review aimed to synthesize all the available data on these prion-family members and their relations with reproductive processes, mainly in the gonad of both sexes.

\section{Keywords: prion, Doppel, Shadoo, PRT, reproduction, gonads}

\section{INTRODUCTION}

In Eutherian mammals, the reproductive system is composed by gonads (testes and ovaries) and the genital tract (male: penis, prostate, seminal vesicle, vas deferens, epididymis; female: vulva, vagina, uterus, and oviduct). Gonads produce sex hormones and gametes (sperms and oocytes), whereas the genital tract provides a suitable environment for the maturation and transport of gametes, the fertilization and implantation of the eggs. The differentiation of reproductive organs follows a specific and variable chronology according to species. In every case, the sex determination occurs immediately at fertilization with the addition of male and female gamete genomes. This step determines the genetic sex of the embryo and induces latter on the differentiation of gonads (arising from mesonephros, a transient embryonic kidney) toward a testicular (XY) or an ovarian (XX) differentiating pathway (DeFalco and Capel, 2009; for review; Figure 1). The undifferentiated gonad is composed by a germinal and two somatic cell-lineages. Each somatic line presents a double potentiality and will be turned toward a specific gonadal fate depending of the genes involved in sex determination, with SRY (Sexdetermining Region of Y) being at the top of them (Kashimada and Koopman, 2010; for review). In somatic cell populations, we distinguish: (1) the supporting cells, which will differentiate into Sertoli cells in males and into follicular (also called granulosa) cells in females (these cells are responsible for the growth and the maturation of the germ line); (2) the steroidogenic cells, which will differentiate in Leydig cells in male and theca cells in female (Figure 1). The phenotypic sex, which depends on the gonadal sex and its hormonal production, is set up in many successive steps during development from early gonad differentiation until adulthood. Testes produce androgens and $\mathrm{AMH}$ (Anti-Müllerian Hormone) which are responsible for the differentiation of the genital tract toward the male pathway. Without these hormones the genital tract will differentiate into the female pathway.

Most of the major genes involved in gonad differentiation have been discovered through human genetic studies of DSD (Disorders of Sex Differentiation) cases, but many other genes were found to be expressed in gonads following high throughput mRNA sequencing or other expressional studies. Most of the genes of this last category could putatively be involved in gonadal processes but their role remains to be defined. Among these genes are those of the prion-family. Notably, $P R N D$ has been shown to be essential for testicular function in several species (Behrens et al., 2002; Paisley et al., 2004; Kocer et al., 2007). The most studied gene in the prion family is $P R N P$ which encodes a cell surface glycoprotein, the prion protein $\left(\mathrm{PRP}^{\mathrm{C}}\right)$. An infectious isoform of PRP ${ }^{c}\left(\mathrm{PRP}^{\mathrm{sc}}\right)$ has been shown to be the major component of "Prion," the etiological agent of transmissible spongiform encephalopathies (TSEs). These fatal neurodegenerative disorders include Creutzfelt-Jacob disease (CJD) in humans, bovine spongiform encephalopathy and scrapie in bovidae (Prusiner, 1998).

\section{THE PRION GENE FAMILY COMPRISES FOUR MEMBERS}

The "prion gene complex" encompasses four members named $P R N P, P R N D$ (downstream prion protein-like gene), PRNT (prion protein testis-specific gene), and SPRN (shadow of the 


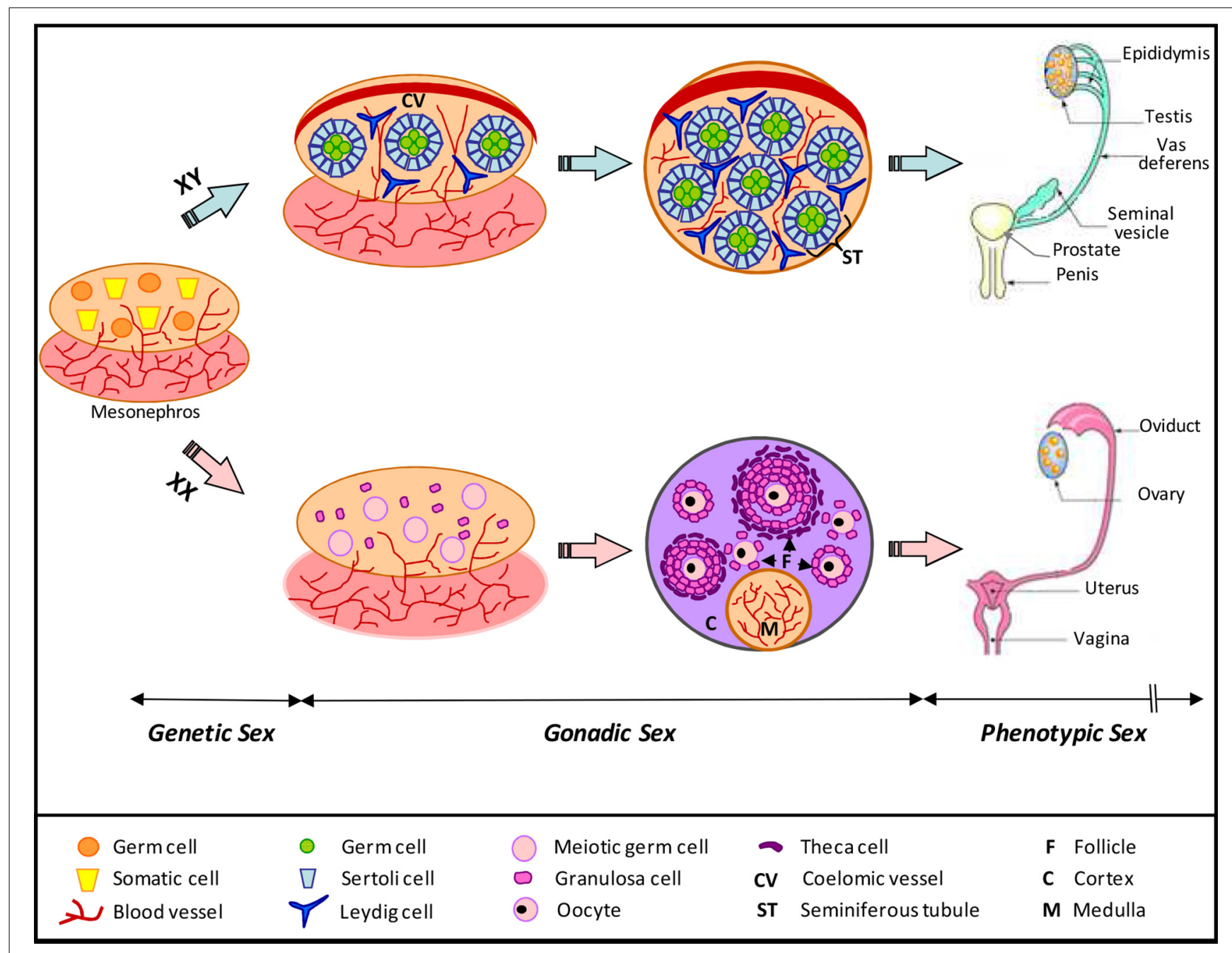

FIGURE 1 | Schematic representation of mammalian gonad differentiation. The genetic sex directs the development of the bipotential gonad toward a male or female gonadal fate. Three cellular types are present in differentiating gonad: somatic supporting cells, somatic steroid-producing cells, and germinal cells. Male and female somatic supporting cells have a common origin and differentiate respectively in Sertoli and granulosa cells. Steroidogenic cells will differentiate in Leydig cells in testis and theca cells in ovary. Testicular-specific features include the formation of the coelomic arterial vessel and of the seminiferous tubules formed by germ and Sertoli cells. Ovarian-specific features are in a chronological order: (i) entry of germ cells into meiosis, (ii) establishment of cortical and medullar compartments, and (iii) formation of follicles, which contain oocytes surrounded by granulosa cells. In agreement with the genetic sex, the development of the phenotypic sex is achieved with the differentiation of the genital tract: epididymis, vas deferens, seminal vesicle, prostate, and penis in males; oviduct, uterus and vagina in female (Adapted from DeFalco and Capel, 2009; for review). prion protein gene). In mouse, sheep, cattle, and rat, the PRNP gene is composed of three exons, whereas only two are present in humans (Yoshimoto et al., 1992; Saeki et al., 1996; Lee et al., 1998; Figure 2). Depending on the studied species, PRND is located $16-52 \mathrm{~kb}$ downstream of PRNP and PRNT 3 and $6 \mathrm{~kb}$ downstream of human and cattle PRND, respectively (Moore et al., 1999; Comincini et al., 2001; Essalmani et al., 2002; Makrinou et al., 2002; Kocer et al., 2007). PRND and PRNT share with PRNP the same genomic cluster and possibly result from a duplication, that occurred early during eutherian species divergence, of $P R N P$ and $P R N D$, respectively. As $P R N P, P R N D$ structure can vary from two to three exons between species, whereas $P R N T$ has two exons in humans (Comincini et al., 2001; Makrinou et al., 2002; Figure 2). The same organization of PRNT was predicted in cow, sheep, horse, dog and primates whereas this gene seems to be absent in rodents (Premzl et al., 2004; Harrison et al., 2010; Figure 2). SPRN is not part of the PRNP genomic locus, and is located on another chromosome. SPRN comprises two exons and its structure is conserved in fishes and mammals (Premzl et al., 2003; Figure 2). Some of the prion-family genes produce different transcripts of variable compositions and numbers according to the species.

The mammalian PRNP encodes the PRP protein $\left(\mathrm{PRP}^{\mathrm{c}}\right)$ that contains several distinct domains, including an $\mathrm{N}$-terminal signal peptide, an octapeptide repeat domain, a highly conserved hydrophobic segment and a C-terminal hydrophobic region which contains a glycosylphosphatidylinisitol (GPI) anchor (Figure 3A). This glycoprotein possesses two N-linked 

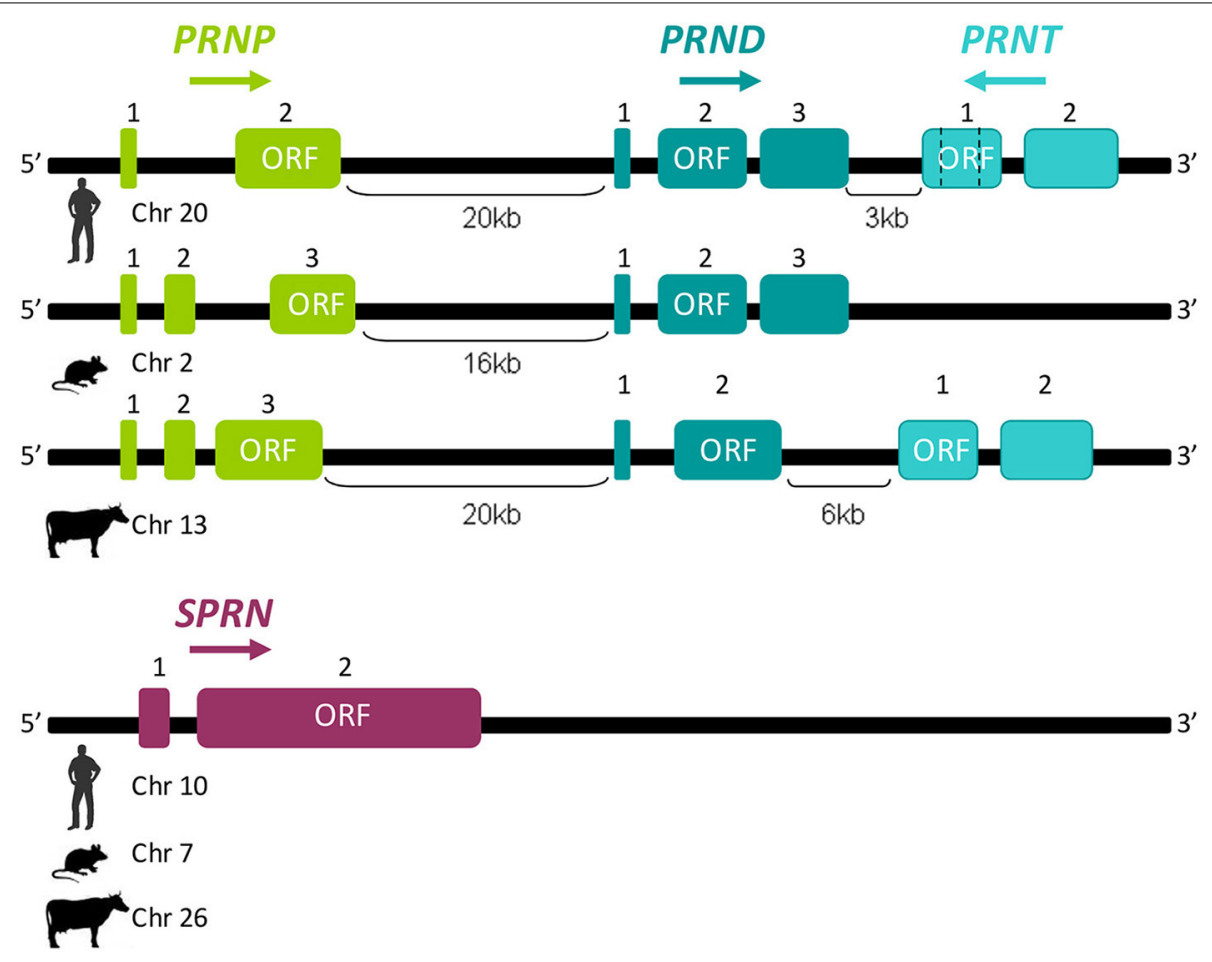

FIGURE 2 | Schematic structural representation of prion genes family members. PRNP, PRND, and PRNT are clustered on the same genomic locus. The distance between PRNP, PRND, and PRNT are given in kilobases $(\mathrm{kb})$; according to species, the number of exons could be variable. SPRN consist of two exons and is located on another chromosome in all studied species. Arrows indicate the relative orientation of the genes. Chromosomes carrying these genes are annotated near each species symbols. For each gene, the open reading frame (ORF) is indicated on relevant exons. glycosylation sites and exists in bi-, mono-, and un-glycosylated forms (Figure 3A). Its secondary structure is defined by the presence of three $\alpha$-helices and two $\beta$-strands (Harris, 1999; for review; Figures 3A,B). The mature Doppel protein (DPL) encoded by $P R N D$ is a protein which resembles a N-terminally truncated $\mathrm{PRP}^{\mathrm{C}}$ protein lacking the octamer repeats (Figure 3 ). In contrast, SPRN encodes the Shadoo protein (SHO) which shares with $\mathrm{PRP}^{\mathrm{c}}$ a similar N-terminal region with a basic repeat region and a hydrophobic domain (Watts and Westaway, 2007; for review; Figure 3). Few data are available concerning the structure of PRT, the PRNT-encoded protein (Makrinou et al., 2002). No signal peptide was predicted for the 94 aa PRT protein, suggesting it could be an intracellular protein (Premzl and Gamulin, 2007). In bovine, PRNT encodes for an N-terminally truncated protein of 55 aa in length, sharing 55\% identity with its human counterpart (Kocer et al., 2007).

Although $\mathrm{PRP}^{\mathrm{c}}$ and $\mathrm{SHO}$ are mainly expressed in the central nervous system (CNS), these two proteins were also detected in male and female gonads (Bendheim et al., 1992; Tanji et al., 1995; Young et al., 2011). DPL and PRT are described as testis-specific proteins (Moore et al., 1999; Tranulis et al., 2001; Makrinou et al., 2002; Kocer et al., 2007). Nevertheless, a transient expression of DPL has been observed in brain of neonatal mice, but this protein is absent in the CNS of adult healthy animals (Li et al., 2000).

Many studies have been conducted on the role of DPL in testis differentiation but the implication of the other prion proteins in reproduction still remains subjective.

\section{TESTIS-SPECIFIC PRION PROTEINS}

In order to comment on the role of a testis-specific protein, it is necessary to introduce the spermatogenesis process allowing the production of male germ cells, spermatozoa (spz). Three different generations of germ cells are visible at any given time among the epithelial cells of the seminiferous tubule: spermatogonia (sg), spermatocytes (spc), and spermatids (std; Figure 4). During spermatogenesis, developing germ cells undergo several mitotic divisions and two meiotic divisions after translocation through the blood-testis barrier, to the luminal side of the epithelium, that is defined by tight junctions between non-dividing Sertoli cells. The final stage of spermatogenesis, known as spermiogenesis, consists of the complex differentiation of round spermatids into spermatozoa (cell elongation, nucleus condensation, acrosome formation, cytoplasm reduction; Figure 4). Throughout spermatogenesis each cluster of germ cells, derived from a single spermatogonium, is interconnected by cytoplasmic bridges that are important for synchronizing the developing process. Thus, the germ cells can be considered as being isolated cells only after they are released as spermatozoa into the lumen of the seminiferous tubule. Upon release, spermatozoa leave behind excess cytoplasm, in the form of interconnected syncytial chains called cytoplasmic lobes (Sprando and Russell, 1987; Weber and Russell, 1987), which are subsequently engulfed and degraded as residual bodies by the Sertoli cells (Espenes et al., 2006). Then spermatozoa are stored in epididymis and undergo maturation processes necessary to acquire motility and capacity to fertilize. Final maturation is 


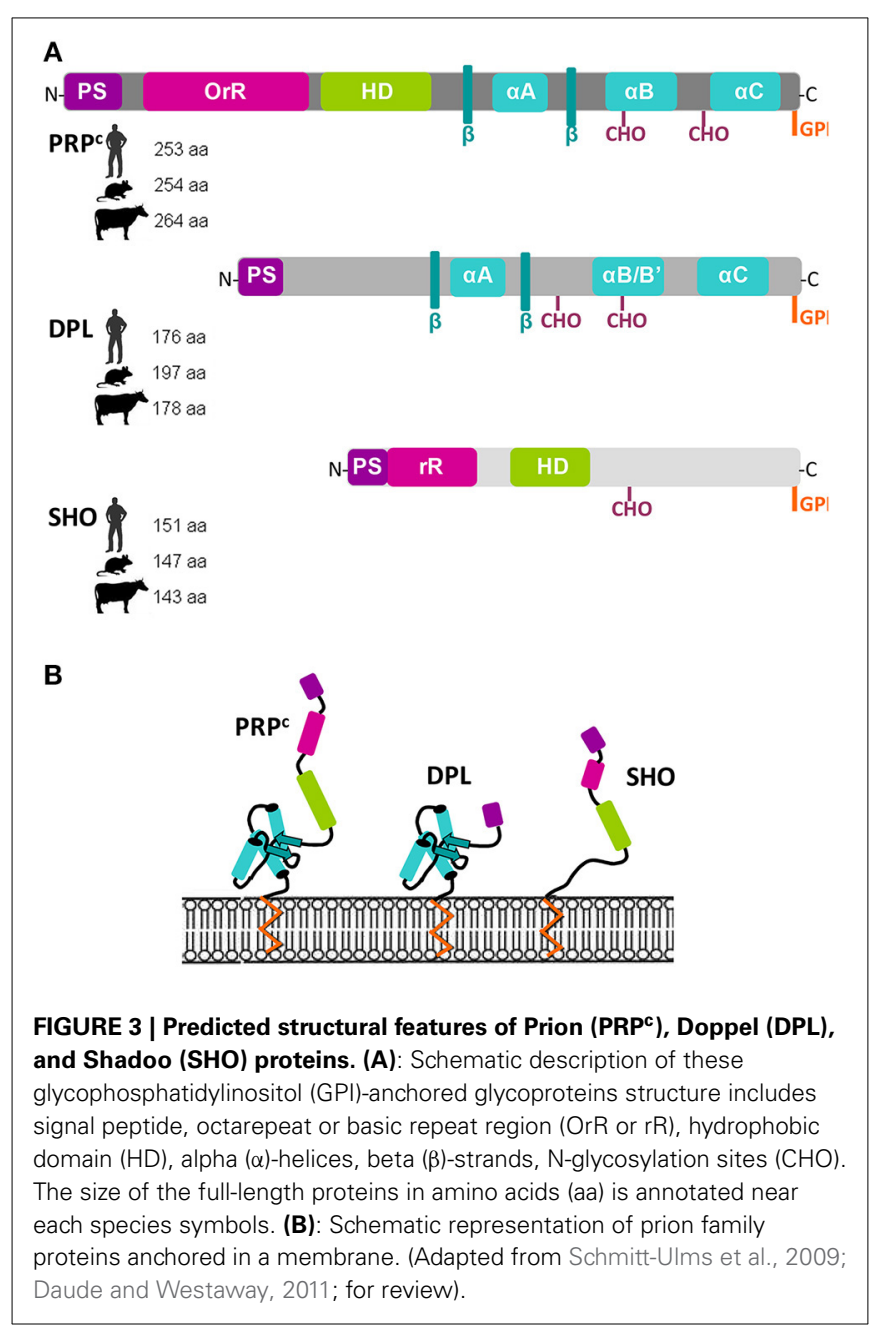

completed in the female reproductive tract where spermatozoa acquire the capacities to fertilize oocytes. This last step called capacitation ended with acrosome reaction which consists on the fusion of the acrosome and oocyte membranes, allowing fertilization.

Two members of the prion-gene family could be considered as testis-specific proteins, $P R N D$ and PRNT. PRND/DPL expression has been studied mainly during spermatogenesis in many species. The first common observation is that DPL is expressed in Sertoli cells at various concentrations according to the species (Westaway, 2004; Rondena et al., 2005; Serres et al., 2006; Kocer et al., 2007; Figure 5). Nevertheless, in germ cells, the localization of DPL is less comparable between animals. For example in bovidae, DPL is present early in primordial germ cells in goat fetal gonads (Kocer et al., 2007) and in bovine, this protein is expressed in all stages of male germ cell development during spermatogenesis (spermatogones to ejaculated spermatozoa, Rondena et al., 2005; Figure 5). In contrast, DPL is only detected in spermatids at final stages of spermiogenesis in ovine, human and mice, (Behrens et al., 2002; Espenes et al., 2006; Serres et al., 2006; Figure 5). Interestingly in ram, DPL is observed in spermatids during the elongation process, in Sertoli cells after sperm release and is completely absent in spermatozoa (Espenes et al.,
2006). Authors suggest that DPL is present in cytoplasmic lobes of maturing spermatids that culminate in DPL concentration in residual bodies which are subsequently released by spermatids then engulfed by Sertoli cells. DPL seems not to be detected in spermatozoa. However, sperm supplementation with recombinant ovine DPL protein during in vitro capacitation, significantly improves spermatozoa motility, vigor, viability and fertilization rate (Pimenta et al., 2012a). At this step we can proposed that DPL expression in ovine ejaculated sperm may be under the threshold of the detection limit of the method and the antibodies used. Otherwise, DPL could be produced by another cell type in the genital tract thus influencing the behavior of spermatozoa. This hypothesis was also suggested in human by Peoc'h and collaborators which completed previous studies by the localization of DPL on the flagella of epididymal and mature spermatozoa, and in seminal plasma (Peoc'h et al., 2002). As DPL seems to be transiently expressed in spermatids but is not detected in differentiated testicular spermatozoa, these authors considered that DPL could be acquired during the maturation of spermatozoa through the epididymis, as it has been described for other GPIanchored proteins on spermatozoa (Peoc'h et al., 2002). Serres and collaborators reinforced this hypothesis by the observation of a DPL-staining in epithelial cells of the boar epididymis, suggesting a possible epididymal origin of DPL and a potential role during spermatozoa maturation (Serres et al., 2006). The transient presence of DPL in the final stages of spermiogenesis points an important role of this protein in the final remodeling of spermatids prior to their release into the testicular seminiferous lumen. The role of DPL in this spermiogenesis process was completely demonstrated by the analysis of mouse Prnd knock-out lines. Indeed, ablation of Prnd (Prnd ${ }^{-/-}$) in two different mouse lines lead to infertile males with different sperm phenotypes.

The Prnd ${ }^{-/-}$mouse line with a 129/Ola genetic background produced low numbers of spermatozoa with poor motility and abnormal nuclei and acrosomes, greatly affecting the fertilization process. Indeed, sperm from DPL-deficient mice appears to be unable to undergo the normal acrosome reaction that is necessary to penetrate the zona pellucida of the ovum and $\mathrm{Prnd}^{-/-}$males are completely sterile (Behrens et al., 2002).

The second $\mathrm{Prnd}^{-/-}$mouse line produced on a mixed C57BL6/CBA genetic background produced a normal number of motile spermatozoa but these spermatozoa had an altered chromatin structure and DNA damages that induce an early arrest of embryo development (Paisley et al., 2004). A common phenotype between both $\mathrm{Prnd}^{-/-}$mice is a loss of sperm head integrity.

In conclusion, the localization of DPL on both somatic (Sertoli cells) and germinal cells strongly suggests that this protein plays a major role in male fertility. In most species, its expression in testicular germ cells was detected at late stage of spemiogenesis, principally in spermatids with a transient presence in acrosome. These data show that DPL is implicated in normal acrosome genesis and thus in spermatozoa fertilizing ability. Supplemental roles could be attributing to DPL by its presence at earliest stages of testis development in bovine and goats, suggesting an involvement in germinal cell ontogeny. Moreover, DPL has also been detected in goat fetal Leydig cells (steroidogenic cells) where its role remains to be defined (Kocer et al., 2007). Finally some roles 


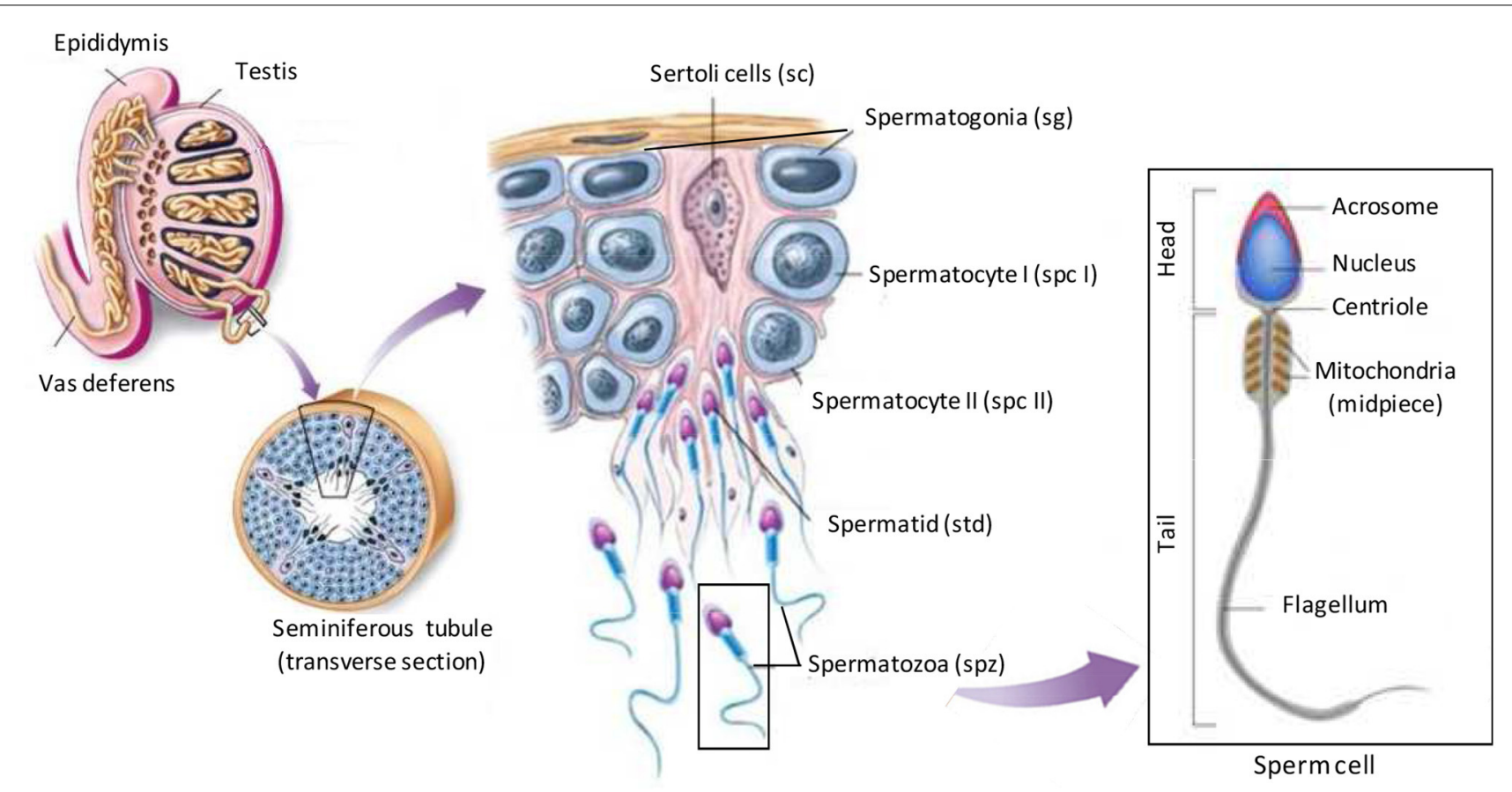

FIGURE 4 | Illustration of spermatogenesis. Spermatogenesis occurs within the seminiferous tubules of the testes of a post pubescent male. Diploid primordial germ cells (also called spermatogonia; sg) near the basal lamina of the seminiferous tubules undergo an initial mitotic division to produce diploid primary spermatocytes (spc I). Nearly half the primary spermatocytes produced remain near the basal lamina to continue to divide mitotically, thus allowing spermatogenesis to be continuous during male's reproductive lifespan. Other primary spermatocytes migrate toward the lumen of the seminiferous tubules and begin to undergo meiosis I, resulting in haploid secondary spermatocytes (spc II). These secondary spermatocytes further divide through meiosis II, producing haploid spermatids (std). Mature sperm cells (spermatozoa; spz) capable of fertilizing an egg develop from spermatids through the final stage called spermiogenesis. In this stage specific regions of the spermatid differentiate into the head, mid-piece, and the tail of the sperm cell. Within the head, an acrosomal space is developed which houses specific enzymes required for fertilization. Specialized acrosomal membranes that are pertinent for fertilization also differentiate in the head of the sperm. A

flagellum develops as a means of motility near the posterior aspect which is fuelled by the abundance of mitochondria in the mid-piece of the sperm cell. (Adapted from buffonescience9.wikispaces website). of DPL in ovarian differentiation couldn't be discarded since DPL has been detected in female germ cells of goat fetuses and in granulosa cells and follicular fluid in bovine (Rondena et al., 2005; Kocer et al., 2007). This last observation reinforces the idea that DPL may contribute to regulate fertility, since follicular fluid has been shown to influence sperm mobility and fertility (Rodriguez et al., 2001).

In order to pinpoint putative other reproductive roles of DPL, it will be of great interest to engineer PRND mutant animals in mammalian species other than mice. For the sex-differentiating process, it is know that the mouse species remains less sensible to gene dosage and haplo-insufficiency than humans. Furthermore, $P R N D$ expression profiles suggest additional roles for DPL in goat testis differentiation compare to mice (Kocer et al., 2007). Accordingly, $P R N D$ gene ablation in goats is currently under investigation in our laboratory that has recently succeeded in such technologies (Boulanger et al., 2014).

Three isoforms of human PRNT have been described and are exclusively expressed in the adult testis, thus absent in fetal tissues including testis (Makrinou et al., 2002). In goats, PRNT is weakly and stochastically expressed in both testes and ovaries at various developmental stages, suggesting that the expression pattern of this gene differs between ruminant and human or, most probably, that ruminant PRNT is a pseudogene (Kocer et al., 2007). By contrast, recent results demonstrate that PRT is found in the ram germinal cells. Notably, PRT expression is localized in the nuclei of spermatogonia, spermatocytes, spermatids and in the sperm acrosome. These observations suggest that ovine PRNT could be a translated protein-coding gene, pointing to a role for PRT in the ram spermatogenesis, throughout spermatogenic cell proliferation and sperm maturation (Pimenta et al., 2012b). However, it is difficult to conclude on a real role of PRT during spermatogenesis. The lack of PRT detection in others species, supports the hypothesis that PRT could be a pseudogene.

\section{PRPC AND ITS SHADOW}

In the $\mathrm{CNS}, \mathrm{PRP}^{\mathrm{c}}$, and $\mathrm{SHO}$ present a partially reciprocal pattern of expression, suggesting a common function of these two proteins in neuronal cells. This overlapping expression leads to Shadoo protein designation (Shadoo is the Japanese word for shadow) and this protein was considered as the putative hostencoded protein that compensates for the lack of $\mathrm{PRP}^{\mathrm{c}}$. Although $\mathrm{PRP}^{\mathrm{C}}$ and $\mathrm{SHO}$ are present in gonads, their single and/or common roles are not established in reproductive biology.

$\mathrm{PRP}^{\mathrm{c}}$ has been more studied and was detected on spermatozoa of different species including human, cattle and mouse 


\begin{tabular}{|c|c|c|c|c|c|c|}
\hline \multicolumn{7}{|l|}{ TESTIS } \\
\hline fetuses germ cells & $\checkmark$ & & & & & \\
\hline Spermatogones & & $\checkmark$ & & & & \\
\hline Spermatocytes & & $\checkmark$ & & & & \\
\hline Spermatids & & $\checkmark$ & $\checkmark$ & $\checkmark$ & $\checkmark$ & \\
\hline Spermatozoa (spz) & & $\checkmark$ & & & & \\
\hline Sertoli cells & $\checkmark$ & $\checkmark$ & $\checkmark$ & $\checkmark$ & $r$ & $\checkmark$ \\
\hline Leydig cells & $\checkmark$ & & & & & \\
\hline \multicolumn{7}{|l|}{ EPIDIDYMIS } \\
\hline Epididymal epithelial cells & & & $?$ & $?$ & & $\checkmark$ \\
\hline Epididymal spz & & & & $\checkmark$ & & \\
\hline EJACULATED SPZ & & $\checkmark$ & & $\checkmark$ & $\checkmark$ & \\
\hline SEMINAL PLASMA & & & & $\checkmark$ & & \\
\hline \multicolumn{7}{|l|}{ OVARY } \\
\hline fetuses germ cells & $\checkmark$ & & & & & \\
\hline \multicolumn{7}{|l|}{ Qocytes } \\
\hline Granulosa cells & & $r$ & & & & \\
\hline Folicular fluid & & $\checkmark$ & & & & \\
\hline
\end{tabular}

FIGURE 5 | Table summarizing the cellular localization of Dopple (DPL) in gonads of various species.

(Shaked et al., 1999) but the nature of $\mathrm{PRP}^{\mathrm{c}}$ isoforms on spermatozoa is debated and appears different according to antibodies. A first study showed the presence of $\mathrm{PRP}^{\mathrm{c}}$ on epididymal sperm extracts from epididymis of mouse and bovine and from ejaculated spermatozoa from bovine and human (Figure 6). The molecular weight of $\mathrm{PRP}^{\mathrm{c}}$ in epididymal sperm cells was similar to that of the brain (control tissue) whereas in mature sperm cells, the $\mathrm{PRP}^{\mathrm{c}}$ isoform detected is smaller and C-terminallytruncated. Authors suggested that the C-terminal portion of the $\mathrm{PRP}^{\mathrm{c}}$ is removed during the process of sperm maturation in epididymis and that the protein is inserted via its N-terminal part in the membrane of ejaculated sperm (Shaked et al., 1999). In contrast, Peoc'h group demonstrated that $\mathrm{PRP}^{\mathrm{c}}$ was recognized on sperm membranes by antibodies binding to the C-terminus part of the protein, suggesting that only $\mathrm{N}$-terminally truncated fragments of $\mathrm{PRP}^{\mathrm{c}}$ are present in these cells in the human species. In addition in human testes, 3 isoforms of $\mathrm{PRP}^{\mathrm{c}}$, an unglycosylated full-length and two N-terminally truncated proteins, are also detected in spermatocytes and spermatids (Peoc'h et al., 2002; Figure 6). Differences in the nature of $\mathrm{PRP}^{\mathrm{c}}$ truncated (C- or Nterm) could be due to differences in the protocol for preparing spermatozoa extracts that could affect proteolysis differentially, or to the antibodies used. Studies in ram supports the work of Shaked and collaborators by demonstrating that one major glycosylated C-terminally truncated $\mathrm{PRP}^{\mathrm{c}}$ isoform is associated with sperm from testis, cauda epididymis and semen and also in sperm cytoplasmic droplets that are released during maturation (Ecroyd et al., 2004; Figure 6). Other $\mathrm{PRP}^{\mathrm{c}}$ isoforms were compartmentalized within cauda epididymal fluid and semina plasma (Ecroyd et al., 2004). Indeed, Gatti and colleagues demonstrated the synthesis and secretion of soluble $\mathrm{PRP}^{\mathrm{c}}$ by the epithelial cells lining the ram epididymis (Figure 6). These cells produce large quantities of a specific isoform of $\mathrm{PRP}^{\mathrm{c}}$ that seems to be processed post-secretion in different ways during epididymal transit. In ovine spermatozoa, different forms of $\mathrm{PRP}^{\mathrm{C}}$ have been found, as reported previously for others species (Shaked et al., 1999), that seem to be inserted into the sperm membrane mainly during ejaculation (Gatti et al., 2002). In summary, both glycosylated and proteolytic isoforms of $\mathrm{PRP}^{\mathrm{c}}$ are present in the male reproductive tract. However, the main isoforms differ between the sperm and the reproductive fluid, suggesting only a low extend of exchange between these two compartments. By studying Prnp deficient mice, a protective role of $\mathrm{PRP}^{\mathrm{c}}$ against copper toxicity has been proposed since sperm cells originating from $\mathrm{Prnp}^{-/-}$mice were significantly more susceptible to high copper concentrations than sperm from wild-type mice (Shaked et al., 1999). The presence of an anti-oxidant defense in the sperm-surrounding media is highly important, especially during passage and storage in the epididymis, since these germinal cells lack the molecular machinery to regenerate damaged lipids and proteins. Nevertheless, Prnp null mice are fully fertile and the ablation of Prnp in Prnd ${ }^{-/-}$ mice has no additional effect on the phenotype described for 


\begin{tabular}{|l|c|c|c|c|}
\hline \multicolumn{1}{|c|}{} & P P & P & & \\
\hline TESTIS & $\checkmark$ & & & \\
\hline Spermatogonia & $\checkmark$ & & & \\
\hline Spermatocytes & & & & $\checkmark$ \\
\hline Spermatids & & & & \\
\hline Spermatozoa (spz) & & & & \\
\hline Sertoli cells & & & & \\
\hline Leydig cells & & & & $\checkmark$ \\
\hline EPIDIDYMIS & $\checkmark$ & $\checkmark$ & & $\checkmark$ \\
\hline Epididymal epithelial cells & & & & $\checkmark$ \\
\hline Epididymal spz & & & \\
\hline EJACULATED SPZ & $\checkmark$ & & & $\checkmark$ \\
\hline SEMINAL PLASMA & $\checkmark$ & & \\
\hline OVARY & & & & \\
\hline Oocytes & & & & \\
\hline Granulosa cells & & $\checkmark$ & & \\
\hline Theca cells & & & & \\
\hline Folicular fluid & & & & \\
\hline OVIDUCT & & & & \\
\hline UTERUS & & & & \\
\hline
\end{tabular}

FIGURE 6 | Table summarizing the cellular localization of Prion protein (PRPc) in gonads of various species.

Prnd ${ }^{-1-}$ males, suggesting that $\mathrm{PRP}^{\mathrm{c}}$ is not involved in fertilizing capacity of mice spermatozoa, at least under normal breeding conditions (Büeler et al., 1992; Manson et al., 1994; Paisley et al., 2004).

$\mathrm{PRP}^{\mathrm{c}}$ is also present in the female reproductive tract. This protein has been detected in the ovary, oviduct and uterus of pregnant and cyclic ewes (Moudjou et al., 2001; Tuo et al., 2001; Figure 6). In bovine, PRNP is expressed in both theca and granulosa cells of ovarian follicles notably in developing follicles suggesting that it could promote the growth of dominant follicles (Forde et al., 2008; Figure 6). Again, invalidation of this gene did not induce any noticeable fertility defect in the studied females. However, these animals were kept under control breeding conditions and not challenged, through induction of oxidative stresses for example. Such challenges revealed yet undiscovered function of PrP in other organs, such as placenta (Alfaidy et al., 2013), and such experiments would be of interest to further assess the function of $\mathrm{PrP}$ in the gonads.

Although no biological role of SHO has been defined in reproduction, few data are available in mice. Generation of transgenic reporter mice for the gene encoding SHO protein (Sprn) has permitted to show a Sprn-LacZ expression in the male and female gonads. In both cases, staining was cell-specific, in the interstitial Leydig cells in testis and in granulosa cells of ovarian follicle (Young et al., 2011). Leydig cells are the site of testosterone biosynthesis that is required for the development of the male reproductive system, and the initiation and maintenance of spermatogenesis. Deregulation of some genes expressed in Leydig cells such as proliferin-related protein (PRP) result in decreased testosterone production and has an impact on development of male reproductive system and fertility (Zhao et al., 2011). If we consider the testicular SHO localization, could this protein have the same function in male fertility? Another way to determine the function of a protein is to study the ablation of its coding gene. The lack of Sprn in mice has no effect on fertility, as judged by the measurement of the litter size (Daude et al., 2012). Given that DPL is implicated in spermiogenesis and $\mathrm{PRP}^{\mathrm{c}}$ is present on spermatozoa, one can imagine that these close proteins can compensate each other. Sprn invalidation in Prnd ${ }^{-1-}$ mice does not increase the testicular phenotype associated with single Prnd knockout (our unpublished data). In the same way, mice deficient for both $\mathrm{SHO}$ and $\mathrm{PRP}^{\mathrm{c}}$ were also found to be viable and fertile (Daude et al., 2012). By contrast, the Sprn knockdown in $P_{r n p^{-/-}}$mice presents an embryonic lethal phenotype at developmental stage E7.5 (Passet et al., 2012). Discordant results between $S p r n^{\mathrm{KO}} / P r n p^{\mathrm{KO}}$ and $S p r n^{\mathrm{KD}} / P r n p^{\mathrm{KO}}$ could be due to different mice genetic backgrounds used in these studies or to a genetic adaptation of the double knockout animals. Nevertheless, gene-targeting experiments in mice do not allow yet defining a putative role of $\mathrm{SHO}$ in reproduction. 


\section{CONCLUSION}

Among the prion-gene family members, $P R N D$ is yet the sole to have been clearly linked to reproductive biology with a crucial function during the late steps of spermatogenesis. Indeed its gene ablation in mice leads to male infertility. Although expression of the other three members PRNP, PRNT, and SPRN has been demonstrated at mRNA and protein levels in gonads and/or reproductive tracts, their specific reproductive functions, if any, remain to be elucidated. The fact that these putative functions haven't been pointed on by human genetics or gene-targeting in other mammalian species may suggest that these proteins by alone have no critical reproductive functions or that their functions aren't hugely affected by mutational events. Indeed, even if the physiological role of $\mathrm{PRP}^{\mathrm{c}}$ remains unclear in the central nervous system, according to the fact that $P r n p^{-/-}$mice or goats seem to be unaffected and well-being, it is a mis-folding of $\mathrm{PRP}^{\mathrm{c}}$ $\left(\mathrm{PRP}^{\mathrm{sc}}\right)$ that remains highly detrimental for the central nervous system physiology (a sort of gain-of-function mutation). This means that we cannot exclude some detrimental reproductive effects of these proteins without any mutational changes, but with post-translational and/or conformational changes remaining very difficult to pin-point.

\section{ACKNOWLEDGMENTS}

The authors want to thank Sophie Mouillet-Richard and JeanLuc Vilotte for their invitation to submit this manuscript. We also thank Jean-Luc Vilotte for his constructive criticisms. The authors are supported by the French ANR-09-BLAN-0015-01 and ANR-09-GENM-009.

\section{REFERENCES}

Alfaidy, N., Chauvet, S., Donadio-Andrei, S., Salomon, A., Saoudi, Y., Richaud, P., et al. (2013). Prion protein expression and functional importance in developmental angiogenesis: role in oxidative stress and copper homeostasis. Antioxid. Redox Signal. 18, 400-411. doi: 10.1089/ars.2012.4637

Behrens, A., Genoud, N., Naumann, H., Rülicke, T., Janett, F., Heppner, F. L., et al. (2002). Absence of the prion protein homologue Doppel causes male sterility. EMBO J. 21, 3652-3658. doi: 10.1093/emboj/cdf386

Bendheim, P. E., Brown, H. R., Rudelli, R. D., Scala, L. J., Goller, N. L., Wen, G. Y., et al. (1992). Nearly ubiquitous tissue distribution of the scrapie agent precursor protein. Neurology 42, 149-156. doi: 10.1212/WNL.42.1.149

Boulanger, L., Pannetier, M., Gall, L., Allais-Bonnet, A., El Zaiat, M., Le Bourhis, D., et al. (2014). FOXL2 is a female sex-determining gene in the goat. Curr. Biol. 24, 404-408. doi: 10.1016/j.cub.2013.12.039

Büeler, H., Fischer, M., Lang, Y., Bluethmann, H., Lipp, H. P., DeArmond, S. J., et al. (1992). Normal development and behaviour of mice lacking the neuronal cell-surface PrP protein. Nature 356, 577-582. doi: 10.1038/356577a0

Comincini, S., Foti, M. G., Tranulis, M. A., Hills, D., Di Guardo, G., Vaccari, G., et al. (2001). Genomic organization, comparative analysis, and genetic polymorphisms of the bovine and ovine prion Doppel genes (PRND). Mamm. Genome 12, 729-733. doi: 10.1007/s00335-001-2064-4

Daude, N., and Westaway, D. (2011). Biological properties of the PRP-like Shadoo protein. Front. Biosci. 16, 1505-1516. doi: 10.2741/3801

Daude, N., Wohlgemuth, S., Brown, R., Pitstick, R., Gapeshina, H., Yang, J., et al. (2012). Knockout of the prion protein (PrP)-like Sprn gene does not produce embryonic lethality in combinaison with $\mathrm{PrP}^{\mathrm{c}}$-deficiency. Proc. Natl. Acad. Sci. U.S.A. 109, 9035-9040. doi: 10.1073/pnas.1202130109

DeFalco, T., and Capel, B. (2009). Gonad morphogenesis in vertebrates: divergent means to a convergent end. Annu. Rev. Cell Dev. Biol. 25, 457-482. doi: 10.1146/annurev.cellbio.042308.13350

Ecroyd, H., Sarradin, P., Dacheux, J. L., and Gatti, J. L. (2004). Compartmentalization of prion isoforms within the reproductive tract of the ram. Bio. Reprod. 71, 993-1001. doi: 10.1095/biolreprod.104.029801
Espenes, A., Harbitz, I., Skogtvedt, S., Fuglestveit, R., Berg, K. A., Dick, G., et al. (2006). Dynamic expression of the prion-like protein Doppel in ovine testicular tissue. Int. J. Androl. 29, 400-408. doi: 10.1111/j.1365-2605.2005. 00618.x

Essalmani, R., Taourit, S., Besnard, N., and Vilotte, J. L. (2002). Sequence determination and expression of the ovine doppel-encoding gene in transgenic mice. Gene 285, 287-290. doi: 10.1016/S0378-1119(02)00391-8

Forde, N., Rogers, M., Canty, M. J., Lonergan, P., Smith, G. W., Coussens, P. M., et al. (2008). Association of the prion protein and its expression with ovarian follicle development in cattle. Mol. Reprod. Dev. 75, 243-249. doi: 10.1002/mrd.20807

Gatti, J. L., Métayer, S., Moudjou, M., Andréoletti, O., Lantier, F., Dacheux, J. L., et al. (2002). Prion protein is secreted in soluble forms in the epididymal fluid and proteolytically processed and transported in seminal plasma. Biol. Reprod. 67, 393-400. doi: 10.1095/biolreprod67.2.393

Harris, D. A. (1999). Cell biological studies of the prion protein. Curr. Issues Mol. Biol. 1, 65-75.

Harrison, P. M., Khachane, A., and Kumar, M. (2010). Genomic assessment of the evolution of the prion protein gene family in vertebrates. Genomics 95, 268-277. doi: 10.1016/j.ygeno.2010.02.008

Kashimada, K., and Koopman, P. (2010). Sry: the master switch in mammalian sex determination. Development 137:3921-3930 doi: 10.1242/dev.048983

Kocer, A., Gallozzi, M., Renault, L., Tilly, G., Pinheiro, L., Le Provost, F., et al. (2007). Goat PRND expression pattern suggests its involvement in early sex differentiation. Dev. Dyn. 236, 836-842. doi: 10.1002/dvdy.21066

Lee, I. Y., Westaway, D., Smit, A. F., Wang, K., Seto, J., Chen, L., et al. (1998). Complete genomic sequence and analysis of the prion protein gene region from three mammalian species. Genome Res. 8, 1022-1037.

Li, A., Sakaguchi, S., Shigematsu, K., Atarashi, R., Roy, B.C., Nakaoke, R., et al. (2000). Physiological expression of the gene for PrP-like protein, PrPLP/Dpl, by brain endothelial cells and its ectopic expression in neurons of PrP-deficient mice ataxic due to Purkinje cell degeneration. Am. J. Pathol.157, 1447-1452. doi: 10.1016/S0002-9440(10)64782-7

Makrinou, E., Collinge, J., and Antoniou, M. (2002). Genomic characterization of the human protein (PrP) gene locus. Mamm. Genome 13, 696-703. doi: 10.1007/s00335-002-3043-0

Manson, J. C., Clarke, A. R., Hopper, M. L., Aitchison, L., McConnell, I., and Hope, J. (1994). 129/Ola mice carrying a null mutation in PrP that abolishes mRNA production are developmentally normal. Mol. Neurobiol. 8, 121-127. doi: 10.1007/BF02780662

Moore, R. C., Lee, I. Y., Silverman, G. L., Harrison, P. M., Strome, R., Heinrich, C., et al. (1999). Ataxia in prion protein (PrP)-deficient mice is associated with upregulation of the novel PrP-like protein doppel. J. Mol. Biol. 292, 797-817. doi: 10.1006/jmbi.1999.3108

Moudjou, M., Frobert, Y., Grassi, J., and La Bonnardière, C. (2001). Cellular prion protein status in sheep: tissue-specific biochemical signatures. J. Gen. Virol. 82, 2017-2024. doi: 10.1099/vir.0.17776-0

Paisley, D., Banks, S., Selfridge, J., McLennan, N. F., Ritchie, A. M., McEwan, C., et al. (2004). Male infertility and DNA damage in Doppel knockout and prion protein/Doppel double-knoukout mice. Am. J. Pathol. 164, 2279-2288. doi: 10.1016/S0002-9440(10)63784-4

Passet, B., Young, R., Makhzami, S., Vilotte, M., Jaffrezic, F., Halliez, S., et al. (2012). Prion protein and Shadoo are involved in overlapping embryonic pathways and trophoblastic development. PLoS ONE 7:e41959. doi: 10.1371/journal.pone.0041959.

Peoc'h, K., Serres, C., Frobert, Y., Martin, C., Lehmann, S., Chasseigneaux, S., et al. (2002). The human "prion-like" protein Doppel is expressed in both Sertoli cells ans spermatozoa. J. Biol. Chem. 277, 43071-43078. doi: 10.1074/jbc.M206357200

Pimenta, J., Dias, F. M., Marques, C. C., Baptista, M. C., Vasques, M. I., Horta, A. E., et al. (2012a). The prion-like protein Doppel enhances ovine spermatozoa fertilizing ability. Reprod. Domest. Anim. 47, 196-202. doi: 10.1111/j.14390531.2011.01827.x

Pimenta, J., Domingos, A., Santos, P., Marques, C. C., Cantante, C., Santos, A., et al. (2012b). Is prnt a pseudogene? Identification of ram Prt in testis and ejaculated spermatozoa. PLoS ONE 7:e42957. doi: 10.1371/journal.pone. 0042957

Premzl, M., and Gamulin, V. (2007). Comparative genomic analysis of prion genes. BMC Genomics 8:1. doi: 10.1186/1471-2164-8-1 
Premzl, M., Gready, J. E., Jermiin, L. S., Simonic, T., and Marshall Graves, J. A. (2004). Evolution of vertebrate genes related to prion and shadoo proteinsclues from comparative genomic analysis. Mol. Bio. Evol. 21, 2210-2231. doi: $10.1093 / \mathrm{molbev} / \mathrm{msh} 245$

Premzl, M., Sangiorgio, L., Strumbo, B., Marshall Graves, J. A., Simonic, T., and Gready, J. E. (2003). Shadoo, a new protein highly conserved from fish to mammals and with similarity to prion protein. Gene 314, 89-102. doi: 10.1016/S0378-1119(03)00707-8

Prusiner, S. B. (1998). Prions. Proc. Natl. Acad. Sci. U.S.A. 95, 13363-13383. doi: 10.1073/pnas.95.23.13363

Rodriguez, H., Torres, C., Valdes, X., Guerra, H., Pastor, L. M., Maccallini, G., et al. (2001). The acrosomic reaction in stallion spermatozoa: inductive effect of the mare preovulatory follicular fluid. Biocell. 25, 115-120.

Rondena, M., Ceciliani, F., Comazzi, S., Pocacqua, V., Bazzocchi, C., Luvoni, C., et al. (2005). Identification of bovine doppel protein in testis, ovary and ejaculated spermatozoa. Theriogenology 63, 1195-1206. doi: 10.1016/j.theriogenology.2004.06.009

Saeki, K., Matsumoto, Y., Hirota, Y., Matsumoto, Y., and Onodera, T. (1996). Threeexon structure of the gene encoding the rat prion protein and its expression in tissues. Virus Genes 12, 15-20. doi: 10.1007/BF00369996

Schmitt-Ulms, G., Ehsani, S., Watts, J. C., Westaway, D., and Wille, H. (2009). Evolutionary descent of prion genes from the ZIP family of metal ion transporters. PLoS ONE 4:e7208. doi: 10.1371/journal.pone.0007208.

Serres, C., Peoc'h, K., Courtot, A. M., Lesaffre, C., Jouannet, P., and Laplanche, J. L. (2006). Spatio-developmental distribution of the prion-like protein doppel in Mammalian testis: a comparative analysis focusing on its presence in the acrosome of spermatids. Biol. Reprod. 74, 816-823. doi: 10.1095/biolreprod.105.047829

Shaked, Y., Rosenmann, H., Talmor, G., and Gabizon, R. (1999). A C-terminaltruncated $\operatorname{PrP}$ isoform is present in mature sperm. J. Biol. Chem. 274, 32153-32158. doi: 10.1074/jbc.274.45.32153

Sprando, R. L., and Russell, L. D. (1987). Comparative study of cytoplasmic elimination in spermatids of selected mammalian species. Am. J. Anat. 178, 72-80. doi: 10.1002/aja.1001780109

Tanji, K., Saeki, K., Matsumoto, Y., Takeda, M., Hirasawa, K., Doi, K., et al. (1995). Analysis of PRPc mRNA by in situ hybridization in brain, placenta, uterus and testis of rats. Intervirology 38, 309-315.

Tranulis, M. A., Espenes, A., Comincini, S., Skretting, G., and Harbitz, I. (2001). The PrP-like protein Doppel gene in sheep and cattle: cDNA sequence and expression. Mamm. Genome 12, 376-379. doi: 10.1007/s0033500 10285

Tuo, W., Zhuang, D., Knowles, D. P., Cheevers, W. P., Sy, M. S., and O’Rourke, K. I. (2001). Prp-c and Prp-sc at the fetal maternal interface. J. Biol. Chem. 276, 18229-18234. doi: 10.1074/jbc.M008887200

Watts, J. C., and Westaway, D. (2007). The prion protein family: diversity, rivalry, and dysfunction. Biochim. Biophys. Acta 1772, 654-672. doi: 10.1016/j.bbadis.2007.05.001

Weber, J. E., and Russell, L. D. (1987). A study of intercellular bridges during spermatogenesis in the rat. Am. J. Anat. 180, 1-24. doi: 10.1002/aja.1001800102 Westaway, D. (2004). "Inherited prion diseases," in Prion Biology and Diseases, ed S. B. Prusiner (New York, NY: Cold Spring Harbor Laboratory Press), 673-775.

Yoshimoto, J., Iinuma, T., Ishiguro, N., Horiuchi, M., Imamura, M., and Shinagawa M. (1992). Comparative sequence analysis and expression of bovine PrP gene in mouse L-929 cells. Virus Genes 6, 343-356. doi: 10.1007/BF01703083

Young, R., Le Guillou, S., Tilly, G., Passet, B., Castille, J., Beringue, V., et al. (2011). Generation of Sprn-regulated reporter mice reveals gonadic spatial expression of the prion-like protein Shadoo in mice. Biochem. Biophys. Res. Commun. 412, 752-756. doi: 10.1016/j.bbrc.2011.08.049

Zhao, L., Hao, J., Hu, J., Wang, Q., Lü, Z., Wang, L., et al. (2011). Expression of proliferin-related protein in testis and the biological significance in testosterone production. Mol. Cell. Endocrinol. 343, 25-31 doi: 10.1016/j.mce.2011.05.046

Conflict of Interest Statement: The authors declare that the research was conducted in the absence of any commercial or financial relationships that could be construed as a potential conflict of interest.

Received: 18 July 2014; accepted: 12 September 2014; published online: 02 October 2014.

Citation: Allais-Bonnet A and Pailhoux E (2014) Role of the prion protein family in the gonads. Front. Cell Dev. Biol. 2:56. doi: 10.3389/fcell.2014.00056

This article was submitted to Cell Death and Survival, a section of the journal Frontiers in Cell and Developmental Biology.

Copyright () 2014 Allais-Bonnet and Pailhoux. This is an open-access article distributed under the terms of the Creative Commons Attribution License (CC BY). The use, distribution or reproduction in other forums is permitted, provided the original author(s) or licensor are credited and that the original publication in this journal is cited, in accordance with accepted academic practice. No use, distribution or reproduction is permitted which does not comply with these terms. 